\title{
IMPLEMENTASI LEAN CANVAS PADA PROJECT CORPORATE ENTREPRENEURSHIP
}

\author{
Eric Harianto \\ Program Studi Magister Manajemen \\ Fakultas Ekonomi Universitas Ciputra Surabaya \\ UC Town, Citraland, Surabaya \\ eric.harianto@ciputra.ac.id
}

\begin{abstract}
The purpose of this research is to (1) identify project corporate entrepreneurship with the application of lean canvas; (2) identify constraints in the application of lean canvas in corporate entrepreneurship projects; (3) identify the benefits contained in the application of lean canvas in corporate entrepreneurship projects. Data is collected from October 2018 to December 2018. The method used is descriptive research method with qualitative approach. The researcher conducted interviews with 5 informants. The analysis tools used are lean start up and lean canvas. The data analysis techniques used is Creswell data analysis techniques (2014). The results of this study are (1) project corporate entrepreneurship can be implemented in nine lean canvas blocks and can easily see the concept of optimization model and linkages between nine blocks in lean canvas; (2) the most difficult constraints experienced are when filling key metric blocks and unfair advantages in the lean canvas; (3) the researcher can easily analyze project corporate entrepreneurship in determining future strategies in order to find out which projects are effective or not to be continued or developed based on the achievement measured in the key metric blocks in one of the lean canvas blocks and the integration of nine blocks in lean canvas.
\end{abstract}

\begin{abstract}
ABSTRAK
Tujuan dari penelitian ini yakni untuk: (1) mengindentifikasi project corporate entrepreneurship dengan penerapan lean canvas; (2) mengidentifikasi kendala dalam penerapan lean canvas pada project corporate entrepreneurship; (3) mengidentifikasi manfaat yang terdapat dalam penerapan lean canvas pada project corporate entrepreneurship. Data dikumpulkan mulai bulan Oktober 2018 sampai dengan Desember 2018. Metode yang digunakan adalah metode penelitian deskriptif dengan pendekatan kualitatif. Peneliti melakukan wawancara dengan 5 informan. Alat analisis yang digunakan yaitu lean start up dan lean canvas. Teknik analisis data yang digunakan adalah teknik analisis data Creswell (2014). Hasil dari penelitian ini adalah: (1) Project corporate entrepreneurship dapat diimplementasikan di dalam sembilan blok lean canvas dan dapat melihat konsep model optimasi secara mudah serta keterkaitan antar sembilan blok didalam lean canvas. (2) Kendala yang paling sulit dialami adalah pada saat mengisi blok key
\end{abstract}


metric dan unfair advantage di dalam lean canvas. (3) Penulis dapat dengan mudah menganalisis project corporate entrepreneurship dalam menentukan strategi ke depan guna mengetahui project yang dijalankan efektif atau tidak untuk dilanjutkan atau dikembangkan berdasarkan pencapaian yang diukur di dalam blok key metric di salah satu blok lean canvas dan integrasi di dalam sembilan blok pada lean canvas.

Keywords: lean canvas, lean startup, optimization, corporate entrepreneurship.

\section{PENDAHULUAN}

Bangunan atau gedung merupakan suatu sarana untuk mendukung fungsi dan tujuan yang ingin dicapai suatu organisasi. Untuk mempertahankan kondisi sebuah bangunan atau gedung supaya optimal diperlukan pemeliharaan dan perawatan. Pemeliharaan dan perawatan pada suatu gedung sangat diperlukan dengan beberapa alasan diantaranya:

1. Alasan Fungsional.

Bagian dari upaya mempertahankan kinerja gedung (keandalan dan laik fungsi) konsekuensi dari siklus produk.

2. Alasan Ekonomi.

Mencegah kerusakan lebih parah, penanganan terencana dan nilai ekonomi aset.

3. Alasan Legal.

Berdasarkan Peraturan Menteri Pekerjaan Umum Nomor 24/PRT/ M/2008 tentang Pedoman Pemeliharaan dan Perawatan Bangunan Gedung, untuk setiap bangunan gedung perlu adanya perawatan dan pemeliharaan secara rutin.

Sebuah bangunan gedung akan terdiri dari banyak bagian atau komponen. Beberapa bagian atau komponen tersebut diantaranya:

- Komponen arsitektur (jendela, pintu, railing tangga, pagar, cat, plafon dan lain-lain).
- Komponen struktural (pondasi, sloof, kolom, ring balk, dinding pemikul, rangka atap).

- Komponen non struktural (lisplang, partisi, kolom praktis dan lain-lain).

- Komponen mechanical electrical (instalasi listrik, plumbing, AC (Air Conditioner), transportasi gedung, telekomunikasi dan lainnya).

- Komponen fasilitas gedung (peralatan kerja, furniture, tempat parkir, halaman dan lain-lain).

Universitas Ciputra Surabaya adalah salah satu perguruan tinggi swasta yang berkedudukan di Surabaya, Indonesia. Universitas Ciputra didirikan pada tanggal 7 Februari 1990 dan diberikan Surat Keputusan pendirian Perguruan Tinggi tertanggal 31 Mei 2006. Universitas Ciputra terletak di UC Town Citra Land, Sambi Kerep, Surabaya. Universitas Ciputra adalah universitas termuda pertama di Jawa Timur yang meraih akreditasi A untuk akreditasi institusi. Seiring dengan perkembangan yang sangat cepat, Universitas Ciputra pada saat ini telah memiliki 4 gedung berupa 4 Tower yang terbagi atas: UC 1, UC 2, UC 3 dan UC 4 dengan total luas $47.502 \mathrm{~m}^{2}$. Pemeliharaan dan perawatan gedung di Universitas Ciputra dilakukan oleh suatu departemen yaitu Departemen Property Management. 
Dengan semakin bertambahnya gedung yang dimiliki oleh Universitas Ciputra menyebabkan ruang lingkup pemeliharaan juga menjadi semakin besar, khususnya pada pemeliharaan dan perawatan unit AC. Data unit AC yang ada di Universitas Ciputra gedung UC1, UC2, UC3, dan UC4 berjumlah 581 unit AC dengan data posisi AC, lokasi AC dan merek AC seperti terlihat pada Tabel 1, Tabel 2 dan Tabel 3.

Tabel 1

Posisi AC

di Gedung Universitas Ciputra

\begin{tabular}{|c|c|c|c|c|}
\hline LOKASI & POSISI & KET & JUMLAH & TOTAL \\
\hline UC 4 & H & TOWER & 155 & 155 \\
\hline \multirow{2}{*}{ UC 1,2,3 } & H & LT 1 - 3 & 67 & \multirow{2}{*}{199} \\
\cline { 2 - 4 } & V & LT 1 - 3 & 132 & \\
\hline \multirow{2}{*}{ UC 1,2,3 } & H & LT 4 - 8 & 124 & \multirow{2}{*}{ 227 } \\
\cline { 2 - 4 } & V & LT 4 - 8 & 103 & \\
\hline \multicolumn{4}{|c|}{ TOTAL } & $\mathbf{5 8 1}$ \\
\hline
\end{tabular}

Tabel 2

Lokasi AC

di Gedung Universitas Ciputra

\begin{tabular}{|l|c|}
\hline Posisi & Jumlah \\
\hline Horizontal & $\mathbf{3 4 6}$ \\
\hline Vertikal & $\mathbf{2 3 5}$ \\
\hline TOTAL & $\mathbf{5 8 1}$ \\
\hline
\end{tabular}

Tabel 3

Merk AC

di Gedung Universitas Ciputra

\begin{tabular}{|l|c|}
\hline Merk AC & Jumlah \\
\hline Daikin & 311 \\
\hline Honshu & 14 \\
\hline Changhong & 134 \\
\hline General & 10 \\
\hline LG & 111 \\
\hline Panasonic & 1 \\
\hline Total & 581 \\
\hline
\end{tabular}

Dari seluruh unit AC yang ada ditemukan ada 54 Unit AC yang bermasalah dalam kondisi tidak dingin di lokasi UC1, UC2 dan UC3. Dengan banyaknya problem yang ada, maka perlu dilakukan optimalisasi di Departemen Property Management, khususnya di Divisi Mechanical Electrical.

Menurut Kamus Besar Bahasa Indonesia (2008: 986) optimalisasi adalah suatu tindakan, proses atau metodologi untuk membuat sesuatu (sebagai sebuah desain, sistem atau keputusan) menjadi lebih/sepenuhnya sempurna, fungsional atau lebih efektif. Sedangkan dalam Kamus Oxford (2008: 358) "Optimization is the process of finding the best solution to some problem where "best" accords to prestated criteria". Jadi optimalisasi adalah sebuah proses, cara dan perbuatan (aktivitas/kegiatan) untuk mencari solusi terbaik dalam beberapa masalah, di mana yang terbaik sesuai dengan kriteria tertentu.

Lean canvas salah satu metode untuk untuk dapat melakukan optimalisasi dengan langkah awal memetakan problem yang ada untuk dapat mencari solusi.Tujuan dari penelitian ini adalah mengimplementasikan lean canvas di dalam melakukan optimalisasi project corporate entrepreneurship property management Universitas Ciputra Surabaya.

\section{TINJAUAN PUSTAKA \\ Corporate Entrepreneurship}

Corporate entrepreneurship adalah sebuah proses atau aktivitas entrepreneurial yang dilakukan individu atau kelompok di dalam suatu organisasi atau korporasi dengan mengoptimalkan peluang yang ada dan bertujuan untuk menemukan inovasi yang baru, pengembangan bisnis baru, sis- 
tem yang baru untuk dapat meningkatkan optimalisasi dan revenue sebuah organisasi atau perusahaan (Eric Harianto, 2015).

Sharma and Chrisman (1999) membedakan corporate entrepreneurship menjadi tiga, yaitu lahirnya bisnis baru dalam perusahaan, pembaruan strategis dan inovasi. Penciptaan bisnis baru dalam perusahaan disebut dengan corporate venturing. Inovasi dapat dilakukan melalui pemanfaatan pasar baru, penawaran produk baru, atau keduanya. Pembaruan strategis adalah usaha-usaha mewujudkan kewirausahaan dalam perusahaan yang menghasilkan perubahan signifikan dalam bisnis organisasi, struktur dan strategi. Perubahan ini akan mengubah hubungan yang telah dibangun sebelumnya dalam organisasi atau antara organisasi dengan lingkungan eksternal.

Zahra (1996) menjelaskan bahwa corporate entrepreneurship merupakan aktivitas normal dan informal yang bertujuan menciptakan bisnis baru dalam perusahaan yang telah mapan melalui inovasi produk, proses dan pengembangan pasar. Pendapat ini sesuai dengan yang dikemukakan oleh Ginsberg and Guth (1990) bahwa corporate entrepreneurship mencakup dua fenomena utama: penciptaan bisnis baru dalam organisasi yang ada dan transformasi dari organisasi yang ada melalui pembaruan strategi.

\section{Lean Canvas}

Lean canvas adalah suatu modifikasi dari sebuah bisnis model canvas. Bisnis model canvas ini ditemukan oleh Alexander Osterwalder. Bisnis model canvas biasanya diterapkan pada perusahaan-perusahaan yang sudah mempunyai skala besar, sehingga tidak sesuai jika perusahaan yang baru merintis usaha menggunakan model bisnis ini.

Adanya ketidaksesuaian ini mendorong Maurya (2012) untuk mencoba memodifikasi model bisnis canvas menjadi model bisnis yang bisa diterapkan oleh perusahaan baru yang dikenal dengan istilah model bisnis lean canvas. Model bisnis lean canvas sangat sesuai untuk diterapkan di dalam melakukan optimalisasi di project corporate entrepreneurship.

Lean canvas ini adalah pengembangan lebih lanjut dari model bisnis canvas, totalnya ada 9 komponen. Komponen pertama adalah customer segment. Di sini akan ditentukan siapa target pengguna dan yang terkait di dalam project corporate entrepreneurship yang dirancang dan akan dimplementasikan. Customer segment diantaranya adalah target jajaran manajemen perusahaan, konsumen dan pihak yang terlibat di dalam operasional sebuah perusahaan. Salah satu contohnya adalah direktur, manager, staf, dosen, mahasiswa dan vendor terkait.

Komponen kedua adalah problem yang akan menentukan 3 permasalahan utama di dalam project corporate entrepreneurship yang akan diselesaikan. Permasalahan yang ada harus spesifik, detail dan sesuai dengan konteks project corporate entrepreneurship. Komponen ketiga adalah solusi apa yang diberikan untuk dapat menyelesaikan masalah tersebut. Bagian ini berisi setidaknya tiga solusi yang dibuat berdasarkan masalah utama yang ingin diselesaikan pada project corporate entrepreneurship.

Komponen keempat adalah menentukan unique value proposition. Unique value proposition adalah suatu nilai (value) yang unik yang ditawarkan kepada user di dalam melakukan 
optimalisasi project corporate entrepreneurship. Ada 11 value propotition (Osterwalder, 2012):

1. Sesuatu hal yang baru (newness).

2. Meningkatkan kinerja (performance).

3. Mengubah spesifikasi (customization).

4. Tuntas (getting the job done).

5. Desain (design).

6. Status (brand).

7. Harga (price).

8. Hemat (cost reduction).

9. Meminimalisasi risiko (risk reduction).

10. Akses ( accessibility).

11. Kenyamanan (convenience/usability).

Komponen kelima adalah menentukan metode (channel) yang akan digunakan guna menyampaikan uniqe value propotition kepada jajaran manajemen perusahaan, konsumen dan pihak yang terlibat di dalam operasional sebuah perusahaan (customer segment). Channel dibagi menjadi 2 metode yaitu langsung (direct) dan tidak langsung (indirect). Contoh metode langsung adalah pertemuan (meeting), telepon, berbicara (face to face). Sedangkan contoh yang tidak langsung adalah media sosial, email, radio, whatsapp dan line.

Komponen keenam adalah revenue stream yang berisi besarnya optimalisasi yang dapat diimplementasikan di dalam project corporate entrepreneurship. Di dalam komponen keenam dapat diperkirakan hasil optimalisasi yang dapat dilakukan dalam bentuk jumlah biaya penghematan yang akan dilakukan. Komponen ketujuh adalah cost structure yang akan berisi perkiraan budget yang dikeluarkan untuk melakukan optimalisasi project corporate entrepreneurship.
Komponen yang kedelapan adalah menentukan key metric. Key metric adalah sebuah tolak ukur dari progres project corporate entrepreneurship yang bisa diukur dari beberapa indikator yang ditentukan (key performance indicator) untuk dapat mengevaluasi keberhasilan dari project corporate entrepreneurship. Key metric ini akan sangat membantu dalam mengetahui progres dari perkembangan optimalisasi project corporate entrepreneurship yang diukur dalam periode waktu (setiap hari, setiap minggu, setiap bulan atau mungkin juga setiap tahun).

Komponen kesembilan adalah menentukan unfair advantage. Unfair advantage adalah suatu hal yang membuat peneliti dapat memiliki sebuah keuntungan atau kesempatan yang tidak dimiliki oleh orang lain di dalam melakukan optimalisasi project corporate entrepreneurship. Contohnya: pengalaman, kedekatan relasi, memiliki skill khusus. Kesembilan komponen tersebut dapat dilihat pada Gambar 1.

LEAN CANVAS

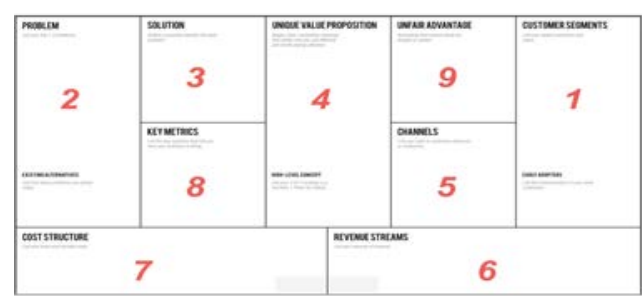

Gambar 1

Lean Canvas

Sumber: Maurya (2012)

\section{Manfaat Lean Canvas}

Manfaat dari lean canvas adalah memudahkan untuk menemukan unique value propotition dari sebuah project corporate entrepreneurship yang dapat dipakai melakukan optimalisasi 
dan efisiensi dari sebuah organisasi atau perusahaan. Sebelumnya ditentukan terlebih dahulu problem utama yang ada dan kemudian memberikan solusi dari problem yang ada. Solusi tersebut akan menghasilkan sebuah nilai atau value yang akan dikategorikan di dalam unique value propotition. Untuk nilai atau value yang ada akan disampaikan ke user melalui channel yang sudah ditentukan. Diharapkan nilai yang ditawarkan ke user bisa sesuai dengan tujuan project corporate entrepreneurship yang dapat memberikan kepuasan kepada user. Hal ini dikaitkan dengan konsep the learn start up. Konsep the learn start up ada 3 stage di dalam membuat sebuah project corporate entrepreneurship yaitu:

1. Problem/Solution Fit (stage1)

2. Product/Market Fit (stage2)

3. Scale (stage3)

Ketiga stage tersebut nampak seperti terlihat pada Gambar 2.

\section{RunningLean}

3 stages of aproduct

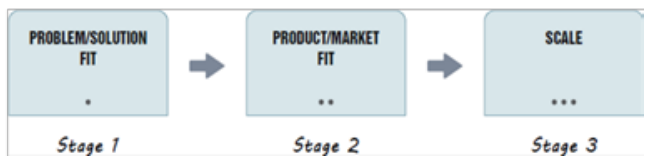

Gambar 2

Konsep Lean Startup

Sumber: Maurya (2012)

Manfaat lain dari lean canvas yaitu adanya pengukuran (scale) dan indikator keberhasilan sebuah project corporate entrepeneurship yang ada di dalam tiga blok yaitu: key metric, revenue stream dan cost structure yang dapat dipakai untuk menentukan project tersebut berhasil atau sebaliknya.
Sebuah project menurut Reis (2011) harus melalui fase build, measure dan learn. Di dalam lean canvas dapat dilihat dan ditentukan indikator keberhasilan bisnis yang akan dibuat sesuai dengan goal setting awal yang sudah ditentukan.

\section{Goal Setting}

Goal setting adalah rencana terperinci tentang bagaimana mewujudkan sebuah project corporate entrepreneurship untuk mencapai tujuan yang sudah ditentukan dan ditetapkan. Goal inilah yang akan memberikan arah untuk melangkah dan membuat timeline untuk dapat mencapai tujuan dan sasaran yang sudah ditentukan. Untuk membuat suatu Goal Setting yang benar digunakan metode tahap awal dari pembuatan Goal Setting (SMART). Istilah SMART pertama kali digunakan Doran (1981) dengan penjelasan sebagai berikut:

1. Specific (Spesifik).

Poin pertama adalah menekankan pentingnya menetapkan target yang spesifik; benar-benar spesifik. Hindari target yang terlalu umum atau kurang mendetail. Target tidak boleh ambigu, harus jelas, dan dipaparkan dengan bahasa yang lugas.

2. Measurable (Terukur).

Setelah menentukan tujuan yang spesifik, tahap selanjutnya adalah mengukur progres (kemajuan) dari tindakan yang sudah dilakukan. Kemajuan akan membantu untuk tetap berada dalam jalur yang benar, menepati tenggat waktu dan merasakan semangat dan euforia ketika memperoleh hasil yang menggembirakan di setiap pencapaian yang membawa lebih dekat kepada tujuan. 
3. Achievable (Dapat Dicapai).

Poin ketiga ini menekankan bahwa target harus realistis dan dapat dicapai (attainable), artinya target tidak boleh dibuat terlalu mudah tapi juga tidak boleh terlalu sulit, sehingga terasa mustahil untuk dicapai.

4. Relevant (Relevan).

Target yang relevan, jika tercapai akan mendorong tim, departemen, dan organisasi lebih maju. Sebuah target yang mendukung atau selaras dengan target-target lainnya akan dianggap sebagai target yang relevan.

5. Time-based (Tenggang Waktu).

Target yang memiliki waktu penyelesaian yang spesifik. Dengan adanya waktu penyelesaian yang spesifik diharapkan dapat mengukur keberhasilan pencapaian target dan melakukan evaluasi pada Goal Setting yang sudah ditetapkan.

\section{Keunikan Lean Canvas}

Salah satu keunikan dari lean canvas terletak pada komponen yang kesembilan. Komponen ini dikenal dengan nama unfair advantage. Definisi dari unfair advantage adalah sebuah keuntungan di mana tidak semua orang memiliki kesempatan atau peluang untuk mendapatkannya. Salah satu contoh yang sering dijumpai di dalam organisasi atau perusahaan adalah keahlian khusus yang hanya dimiliki orang tertentu, sertifikasi khusus, relasi networking yang sangat baik dan bagus, masih ada hubungan saudara dengan pemilik perusahaan, sahabat baik dan berbagai hal khusus yang tidak dapat dimiliki semua orang.

\section{Validated Learning}

Setelah melakukan implementasi lean canvas akan didapatkan ba- nyak pembelajaran. Proses pembelajaran yang didapatkan memberikan banyak manfaat dan masukan untuk menjalankan project corporate entrepreneurship selanjutnya. Pembelajaran tersebut didapat dari keberhasilan ataupun kegagalan di dalam menjalankan project corporate entrepreneurship. Pembelajaran ini yang dikenal dengan nama Validated Learning. Validated Learning adalah suatu proses demonstrasi secara empiris bahwa suatu tim telah menemukan kenyataan berharga mengenai suatu prospek bisnis masa sekarang dan masa depan. Lean start up dikenal sebagai fase learn.

\section{METODE PENELITIAN}

Penelitian ini merupakan penelitian deskriptif dengan pendekatan kualitatif. Ada beberapa hal yang menjadi fokus dari penelitian ini. Beberapa hal tersebut adalah:

1. Mengidentifikasi penerapan lean canvas pada project corporate entrepreneurship:

a. Konsumen (Customer Segment).

b. Masalah (Problem).

c. Solusi (Solution).

d. Proposisi Nilai Unik (Unique Value Proposition).

d. Saluran Distribusi (Channel).

e. Matrik Kunci (Key Metrix).

f. Arus Pendapatan (Revenue Stream).

g. Struktur Biaya (Cost Structure).

h. Keuntungan Khusus (Unfair Advantage).

2. Kendala dalam penerapan lean canvas pada project corporate entrepreneurship.

3. Manfaat atau kegunaan yang terdapat dalam penerapan lean canvas pada project corporate entrepreneurship. 
TEKNIK PENGUMPULAN DATA

Teknik pengumpulan data yang digunakan oleh peneliti antara lain: wawancara dan dokumentasi terhadap 5 informan yaitu pimpinan universitas, Departemen Property Management, mahasiswa, dosen/staf dan vendor AC. Adapun instrumen penelitian yang digunakan adalah: peneliti, pedoman wawancara dan alat penunjang penelitian. Mengacu pada Creswell (2014) data penelitian ini bersifat deskriptif dan peneliti adalah instrumen kunci. Data dikumpulkan dari bulan Oktober 2018 sampai dengan bulan Desember 2018.

\section{HASIL DAN PEMBAHASAN}

Project corporate entrepreneurship yang diteliti pada Departemen Property Management Universitas Ciputra Surabaya khususnya pada Divisi Mechanical and Electrical. Struktur organisasi pada departemen ini dipimpin oleh manajer Property Management di bawahnya terdapat beberapa supervisor. Di dalam penelitian ini observasi akan dilakukan pada Divisi Mechanical Electrical. Di dalam Divisi Mechanical Electrical terdapat supervisor mechanical electrical dan juga kepala teknisi serta asisten kepala teknisi. Divisi ini dibantu oleh satu vendor outsourcing untuk melakukan perawatan AC dengan lokasi UC1, UC2 dan UC3 serta satu vendor outsourcing untuk melakukan perawatan AC dengan lokasi UC4.

Project corporate entrerpreneurship ini akan menggunakan lean canvas untuk melakukan optimasi di lokasi unit AC pada UC1, UC2 dan UC3 yang terdapat 54 unit AC yang tidak berfungsi dengan baik. Beberapa penyebabnya lokasi outdoor AC di UC1, UC2 dan UC3 sebagian besar berada pada posisi vertikal. Posisi vertikal adalah posisi yang hanya bisa dijangkau dengan alat climbing atau gondola, sehingga mengalami kesulitan di dalam melakukan perawatan dan perbaikan AC serta performance vendor AC yang kurang kompeten. Metode yang digunakan untuk dapat melakukan optimalisasi dengan menggunakan lean canvas.

Lean canvas merupakan adaptasi Business Model Canvas (BMC) oleh Alexander Osterwalder yang diciptakan oleh Maurya (2012). Model lean canvas sangat sesuai untuk diterapkan di dalam melakukan optimalisasi di project corporate entrepreneurship. Lean canvas akan diimplementasikan dengan sembilan komponen yang ada di dalamnya.

\section{Konsumen ( Customer Segment)}

Maurya (2012) menyatakan "Sketch a Lean Canvas for each customer segment. As you'll find shortly, the elements of your business model can and will vary greatly by customer segment. I recommend starting with the top two or three customer segments you feel you understand the best or find most promising." Di dalam penerapan lean canvas sesuai dengan konsep teori yang dikembangkan oleh Maurya (2012).

Peneliti mulai mencari target konsumen di dalam project corporate entrepeneurship. Target konsumen yang ada pada project corporate entrepreneurship adalah semua pihak yang terlibat di dalam project optimalisasi diantaranya adalah:

1. Pimpinan Universitas.

Memberikan kebijakan untuk melakukan optimalisasi diantaranya dengan memberikan kebijakan untuk 
melakukan penetapan vendor AC yang ditunjuk, kebijakan di dalam sistem kerja Departemen Property Management, alokasi budgeting di dalam melakukan perawatan AC.

2. Departemen Property Management. Melakukan pemilihan vendor AC sesuai dengan kriteria yang sudah ditetapkan, memonitoring vendor $\mathrm{AC}$, membuat system time line perawatan AC, evaluasi kinerja vendor AC, mengoptimalkan budgeting untuk perawatan serta penggantian unit atau sparepart AC, meminimalisasi gangguan AC yang ada di Universitas Ciputra, meningkatkan performance Divisi Mechanical Electrical.

3. Mahasiswa.

Sebagai pengguna AC yang dapat memberikan feedback dan masukan untuk performance AC pada ruangan yang digunakan sebagai aktivitas belajar.

4. Dosen/Staf.

Sebagai pengguna AC yang dapat memberikan feedback dan masukan untuk performance AC pada ruangan yang dipakai untuk melakukan aktivitas.

5. Vendor AC.

Sebagai pelaksana yang ditunjuk untuk melakukan kegiatan perawatan dan perbaikan unit AC di Universitas Ciputra.

\section{Masalah (Problem)}

Maurya (2012) menyatakan "List the top one to three problems: for the customer segment you are working with, describe the top one to three problems they need solved. Another way to think about problems is in terms of the jobs customers need done”. Di dalam stage 1 harus dilakukan problem and solution fit. Pene- liti pertama kali akan mengidentifikasikan masalah yang dialami oleh konsumen. Hal ini selaras dengan konsep lean startup yang dikembangkan oleh Reis (2011). Dengan mengetahui problem yang ada, maka akan lebih mudah untuk menemukan keinginan konsumen yang selaras dengan tujuan atau outcome yang akan dicapai yaitu optimalisasi project corporate entrepreneurship.

Dalam rangka mengetahui masalah yang dihadapi, peneliti melakukan wawancara terhadap kelima target segmen konsumen, yaitu: pimpinan universitas/rektorat, Departemen Property Management, mahasiswa, dosen/staf dan vendor AC.

Untuk informan yang pertama yaitu rektorat memberikan pernyataan sebagai berikut: “(1) banyaknya kondisi AC di UC 1, 2, dan 3 yang panas yang didapat dari data performance box dari mahasiswa dan staf; (2) monitoring kinerja vendor yang masih lemah karena banyak problem AC yang terbengkalai; (3) time line perawatan unit AC yang masih belum terkontrol." Informan yang kedua yaitu Departemen Property Management memberikan pernyataan sebagai berikut: “(1) kesulitan untuk melakukan koordinasi dengan vendor $A C$, karena untuk UC 1, 2 dan 3 hanya terdiri 1 vendor AC yang diindikasikan performancenya kurang dan tidak ada pertemuan rutin untuk koordinasi perawatan dan perbaikan unit $A C$ karena untuk detail hak dan kewajiban vendor tidak tertulis detail di dalam perjanjian kerjasama; (2) kesulitan untuk mencari vendor yang baru karena lokasi pencucian AC yang sangat sulit pada posisi vertical. Harus menggunakan alat climbing dan gondola; (3) sistem monitoringnya 
masih manual dan tidak disertai dokumentasi baik untuk perawatan AC dan penggantian AC serta belum ada log book database untuk melihat histori baik perbaikan dan perawatan unit AC."

Untuk informan yang ketiga yaitu mahasiswa memberikan pernyataan sebagai berikut: “(1) banyak sekali unit AC yang mengalami kendala; (2) penanganan kendala yang cukup lama (3) terdapat kendala yang berulang." Untuk informan yang keempat yaitu dosen/staf menyatakan sebagai berikut: "(1) banyak unit AC yang mengalami kendala baik bocor air ataupun tidak dingin; (2) penanganan kendala yang lama untuk dilakukan perbaikan; (3) sering terjadi perbaikan unit AC yang berulang pada tempat yang sama."

Untuk informan yang kelima yaitu vendor AC memberikan pernyataan sebagai berikut: “(1) beberapa teknisi ahli yang sudah tidak bekerja lagi di vendor AC yang ditunjuk untuk melakukan pekerjaan perawatan dan perbaikan AC; (2) posisi outdoor AC yang sangat sulit untuk melakukan perbaikan dan maintenance karena selain posisinya tinggi juga harus berhenti pada saat hujan karena sangat berbahaya; (3) unit AC UC 1 , 2, 3 yang kondisinya mayoritas sudah berumur diatas 9 tahun dibutuhkan penanganan lebih dan kurang ada data histori perbaikan pada unit AC."

Dari hasil wawancara tersebut dalam rangka mencari tiga problem utama untuk dimasukkan didalam lean canvas akhirnya disimpulkan 3 problem utama tersebut adalah:

1. Banyaknya kendala AC pada UC1, 2 dan 3 dengan indikator banyaknya AC yang tidak berfungsi normal dan perbaikan yang cukup lama karena hanya mengandalkan 1 vendor AC.

2. Sistem monitoring kinerja vendor AC yang masih perlu diperkuat di dalam database untuk log book perawatan AC dan time line perawatan rutin unit AC.

3. Perjanjian kerjasama yang masih belum mencatat secara detail hak dan kewajiban dari vendor AC.

\section{Solusi ( Solution)}

Berkaitan dengan masalah solusi Maurya (2012) mengungkapkan sebagai berikut: "You are now ready to tackle solution possibilities. Because all you have are untested problems, it is fairly common for them to get reprioritized or completely replaced with new ones after just a few customer interviews. For this reason, I recommend not getting carried away with fully defining your solution just yet. Rather, simply sketch out the simplest thing you could possibly build to address each problem. Bind a solution to your problem as late as possible.

Setelah peneliti mengidentifikasi problem dari customer segment, langkah berikutnya adalah mencari beberapa alternatif solusi untuk menjawab problem yang ada. Peneliti berusaha untuk memberikan solusi yang sederhana yang bisa langsung dilaksanakan di dalam project corporate entrepreneurship.

Untuk mencari solusi dari problem yang ada, peneliti melakukan wawancara terhadap kelima informan yang terlibat langsung di dalam project corporate entrerpreneurship agar dapat menemukan solusi dari setiap problem yang ada. Dari hasil wawancara untuk mencari tiga solusi utama untuk dimasukkan di dalam lean 
canvas akhirnya disimpulkan 3 solusi utama yaitu:

1. Mencari vendor AC yang kompeten untuk menangani AC di UC 1, 2 dan 3 dengan minimal 2 vendor.

2. Membuat sistem kerja dan monitoring kinerja vendor AC yang baru. Semuanya dilakukan secara system base on data (labeling unit AC, log book AC, dokumentasi online, progress action plan, service level agreement, kecepatan penanganan komplain, harga standar sparepart AC).

3. Membuat perjanjian kerjasama kontrak dengan system open contract di mana apabila tidak menunjukkan performance yang baik akan digantikan dengan vendor yang lain. Di perjanjian akan didetailkan tentang hak dan kewajiban serta prosedur pelaksanaan pekerjaan.

Setelah peneliti menentukan solusi dari setiap problem, maka langkah selanjutnya adalah mencari unique value propotition.

\section{Proposisi Nilai Unik ( Unique Value Propotition)}

Peneliti melakukan wawancara terhadap target konsumen untuk dapat menentukan unique value propotition yang tepat sesuai dengan keinginan konsumen. Hal ini sesuai dengan pemaparan sebelumnya di mana stage 2 yaitu produk dan market fit. Unique value propotition terjadi jika antara value yang ditawarkan sesuai dengan keinginan dari konsumen.

Menurut Osterwalder (2012), value propotition adalah solusi yang ditawarkan untuk menyelesaikan permasalahan dan memenuhi kebutuhan dari customer yang dituju di blok customer segment. Value bisa berupa kebaruan (newness), perbaikan perfor- ma berkesinambungan (performance), customization, reliabilitas (getting the job done), desain (design), brand status, harga (price), pengurangan biaya (cost reduction), pengurangan resiko (risk reduction), aksesibilitas (accessibility) dan kenyamanan/penggunaan (convenience/utility).

Tidak semua komponen dari value yang telah dipaparkan di atas dapat digunakan secara sekaligus pada satu jenis produk/jasa. Dari hasil wawancara akhirnya disimpulkan tiga unique value propotition pada project corporate entrepreneurship, yaitu:

1. Performance (hal ini diperlukan karena performance untuk perawatan unit AC masih belum optimal).

2. Getting The Job Done (masih banyak pekerjaan yang tertunda karena sistem kerja yang belum optimal).

3. Cost Reduction (dengan adanya sistem kerja yang optimal diharapkan dapat melakukan efisiensi biaya).

\section{Saluran Distribusi (Channel)}

Menurut Osterwalder (2012) channel memiliki definisi bagaimana agar produk atau jasa yang diciptakan dan dibeli dapat sampai ke tangan konsumen sesuai dengan yang dijanjikan. Channel yang dimaksud di dalam project corporate entrepreneurship ini adalah bagaimana unique value propotition yang sudah ditentukan dapat sampai ke customer segment.

Channel secara praktis dibagi menjadi dua jenis yaitu:

1. Channel Direct yaitu channel langsung, contohnya berhadapan langsung.

2. Channel Indirect yaitu channel tidak langsung, contohnya: media online, instagram, line group, whatsapp, handy talkie). 
Peneliti melihat project corporate entrepreneurship ini menggunakan kedua channel yang ada untuk menyampaikan unique value propotition ke customer segment. Channel Direct dilakukan pada waktu mengadakan meeting rutin koordinasi mingguan dan harian. Channel Indirect dilakukan pada waktu bekerja di lapangan menggunakan handy talkie dan whatsapp group.

\section{Matrik Kunci ( Key Metric)}

Mengenai matrik kunci, Maurya (2012) menyatakan sebagai berikut: "Every business has a few key numbers that can be used to measure how wellit is performing." Sesuai dengan yang ditulis oleh Maurya (2012) untuk menentukan key metric peneliti diharapkan untuk dapat memilih pengukuran yang tepat untuk dapat mengetahui perkembangan project corporate entrepreneurship. Alat ukur ini adalah kunci untuk mengukur apakah project corporate entrepreneurship ini dapat berjalan sesuai dengan target goal setting yang sudah ditentukan. Hal ini sesuai dengan lean startup stage 3 yaitu scalable. Harus ada jangka waktu yang detail untuk dieksekusi.

Peneliti melakukan wawancara untuk mengidentifikasi key metric yang tepat untuk project corporate entrepreneurship, yaitu:

1. Data progres jumlah kendala AC di UC 1, 2 dan 3 diukur secara periodik dalam waktu mingguan dengan target temuan kendala AC dibanding dengan proses pengerjaan di bawah $10 \%$.

2. Data kinerja kecepatan penanganan problem oleh vendor AC dengan kesepakatan SLA tidak boleh lebih dari 1 hari untuk penanganan kendala AC.
3. Data kendala dari improvement box yang didapat dari mahasiswa dan staf pengguna AC di Universitas Ciputra dibawah $5 \%$.

\section{Arus Pendapatan ( Revenue Stream)}

Berkaitan dengan arus pendapatan Maurya (2012) menyatakan sebagai berikut: "The bottom two boxes, labeled "Revenue Streams" and "Cost Structure" are used to model the viability of the business. Rather than thinking interms of three or five year forecasts, take a more ground-up approach." Sesuai dengan yang ditulis oleh Maurya (2012) untuk menentukan revenue stream peneliti mengukur viabilitas dari sebuah project secara praktis.

Menurut (2010) revenue stream adalah penjelasan tentang apa saja halhal yang membuat bisnis mendapatkan pemasukan dari para pelanggannya. Di dalam project corporate entrepreneurship, pendapatan yang didapat adalah dengan melakukan pengurangan biayabiaya yang ada akibat tidak optimal. Project corporate entrepreneurship ini memberikan revenue sebagai berikut:

1. Mengurangi beban biaya pengeluaran pembelian unit AC yang baru dan biaya perawatan unit AC karena perawatan AC sudah dilakukan secara optimal.

2. Mengurangi biaya kerugian efektifitas waktu yang diakibatkan oleh unit AC yang rusak.

3. Mengurangi beban biaya administrasi manual karena sistem dilakukan secara online (paperless).

\section{Struktur Biaya ( Cost Structure)}

Mengenai struktur biaya Maurya (2012) menyatakan sebagai berikut: "List the operational costs you will incur while taking your product to 
market. It's hard to accurately calculate these too far into the future. Instead, focus on the present." Sesuai dengan pendapat Maurya (2012) tersebut untuk menentukan cost structure peneliti diharapkan dapat mencatat pengeluaran operasional guna membuat sebuah project sampai terkirim ke konsumen. Pengeluaran yang dihitung adalah pengeluaran pada saat ini. Pengeluaran yang dikeluarkan untuk melaksanakan project corporate entrepreneurship ini diantaranya:

1. Biaya jasa pembuatan tools dan sistem kontrak vendor yang baru.

2. Biaya yang diperlukan untuk koordinasi meeting (snack dan minuman).

3. Biaya untuk administrasi (ATK, map, kertas dan fotokopi).

\section{Keuntungan Khusus (Unfair Advan- tage)}

Mengenai keuntungan khusus Maurya (2012) menyatakan sebagai berikut: "This is usually the hardest section to fill, which is why I leave it for last. Most founders list things as competitive advantages that really aren't such as passion, lines of code, or features. You have to be able to build a successful business in spite of that, which led Jason Cohen to offer the following definition: $3 A$ real unfair advantage is something that cannot be easily copied orbought. (Jason Cohen, A Smart Bear blog)." Sesuai dengan yang diungkapkan Maurya (2012) langkah untuk menentukan unfair advantage adalah bagian yang sangat sulit. Unfair advantage tidak sama dengan competitive advantage. Unfair advantage adalah sebuah keuntungan di mana tidak semua orang memiliki kesempatan atau peluang untuk mendapatkannya. Unfair advantage untuk project corporate entrepreneurship adalah:

1. Relasi (networking) baik di dalam (internal) maupun dengan pihak luar (external).

2. Keahlian dan pengalaman (skill and experience) khusus di dalam optimalisasi di bidang project yang sejenis.

3. Branding Universitas Ciputra dan Ciputra Group.

Gambar 3 di bawah adalah gambar implementasi lean canvas dari project corporate entrepreneurship.

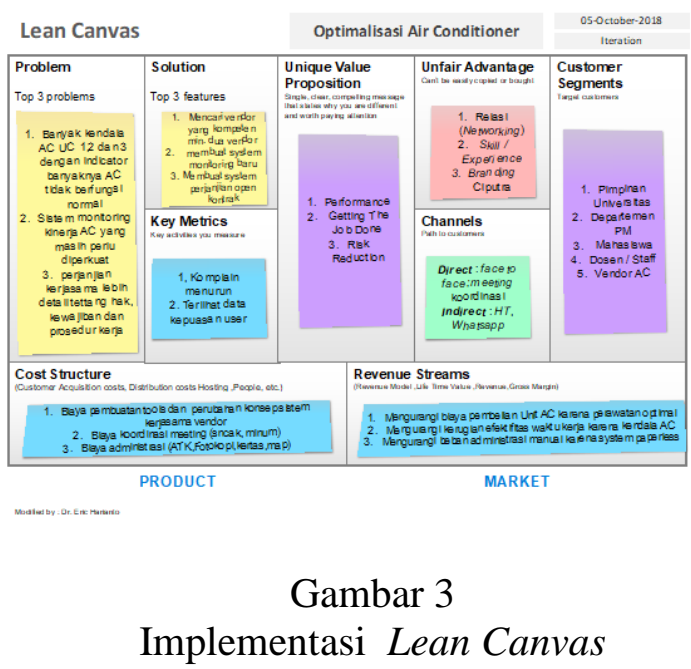

Kendala dalam penerapan Lean Canvas pada Project Corporate Entrepreneurship

Dalam penerapan lean canvas pada project corporate entrepreneurship mengalami beberapa kendala diantaranya adalah:

1. Menentukan problem dan solusi untuk customer segment yang dipilih. Di dalam menentukan problem dan solusi mengalami kendala pada usaha menambah jumlah vendor pemeliharaan unit AC, karena posisi outdoor AC yang vertikal dan hanya dapat dijangkau dengan menggunakan teknik climbing atau gondola 
menyebabkan untuk pemilihan vendor AC tidak banyak yang dapat mengerjakannya dan juga kendala dalam membuat sistem perjanjian kerja sama yang detail dan bersifat open contract karena sebelumnya tidak ada.

2. Menentukan unique value propotition mengalami kendala, karena dalam penentuan performance dan risk reduction sebagai suatu komponen bertolak belakang di dalam project corporate entrepreneurship, tetapi harus dipastikan dengan performance yang baik dan bisa melakukan penurunan biaya untuk perawatan dan perbaikan unit AC.

3. Menentukan key metric mengalami kendala untuk dapat membuat pengukuran guna menilai progres dari project corporate entrepreneurship terutama di dalam pemilihan indikator. Pemilihan indikator penilaian harus tepat agar dapat tepat sasaran.

4. Menentukan unfair advantage adalah hal yang paling sulit, karena ini adalah kunci dari sebuah project corporate entrerpreneurship terutama mencari orang yang memiliki skill khusus, relasi yang luas dan pengalaman spesifik serta pengetahuan yang baik untuk dapat mengerjakan project corporate entrepreneurship.

\section{Manfaat yang Diperoleh dalam Penerapan Lean Canvas pada Project Corporate Entrepreneurship}

Manfaat yang diperoleh dalam penerapan lean canvas pada project corporate entrepreneurship antara lain adalah:

1. Peneliti dapat dengan mudah untuk melihat project corporate entrepreneurship yang terintegrasi di dalam sebuah canvas.
2. Peneliti dapat dengan mudah menentukan strategi ke depan untuk mengetahui project yang dijalankan efektif atau tidak guna dilanjutkan atau dikembangkan berdasarkan pencapaian yang diukur di dalam blok key metric.

\section{Hasil Penerapan Lean Canvas pada Project Corporate Entrepreneurship}

Hasil yang dicapai dari implementasi lean canvas di dalam optimalisasi project corporate entrepreneurship dalam jangka waktu mulai bulan Oktober 2018 sampai dengan Desember 2018 adalah:

1. Vendor AC untuk UC 1, 2 dan 3 diubah menjadi 2 vendor AC. Dengan demikian bargaining power dari Universitas Ciputra menjadi sangat kuat dengan kehadiran 2 vendor, karena apabila vendor yang satu tidak baik akan digantikan dengan vendor yang berikutnya.

2. Penurunan problem AC dari bulan Oktober 2018 yang berjumlah 54 unit AC menjadi 7 unit AC.

3. Performance AC menjadi meningkat dengan adanya service level agreement untuk menangani problem AC dan adanya koordinasi rutin mingguan kedua vendor untuk dapat menciptakan kompetisi yang positif.

4. Perjanjian kerjasama vendor AC dengan sistem open contract di mana apabila performance vendor menurun akan bisa digantikan dengan vendor lain yang lebih kompeten. Hal ini akan menyebabkan vendor untuk menjaga kinerjanya. Perjanjian kerjasama vendor juga dibuat detail berisi hak, kewajiban dan Standard Operating Procedure (SOP) pekerjaan yang jelas, perlengkapan vendor, sanksi apabila 
tidak sesuai dengan service level agreement yang disepakati, harga spare part yang sudah disepakati dan beberapa hal detail lainnya.

5. Sistem monitoring dengan berbasis data dan dokumentasi setiap melakukan perawatan dan perbaikan AC dengan date camera membuat pelaporan menjadi valid dan dapat dipertanggungjawabkan.

6. Adanya label AC yang di dalamnya berisi informasi (lokasi AC, jenis AC, besarnya PK AC, posisi AC vertikal atau horisontal dan tahun pemasangan unit AC) dan log book yang ditempelkan pada setiap unit AC. Dengan adanya label AC dan log book AC akan memudahkan monitoring di dalam melakukan perawatan dan perbaikan unit AC. Pengukuran yang diambil sehabis melakukan service AC, yaitu tekanan freon AC dan ampere AC di mana data ini dapat digunakan untuk dapat menganalisis umur unit AC khususnya outdoor AC. Hal ini berguna untuk melakukan penggantian unit AC sebelum unit AC tersebut rusak.

Tabel 1 di bawah ini menunjukkan Laporan Progres dari AC setelah implementasi lean canvas pada project corporate entrepreneurship.

Tabel 4

Laporan Progres AC

\begin{tabular}{|c|l|c|c|c|c|c|c|c|}
\hline No. & Keterangan & $5 / 10$ & $12 / 10$ & $19 / 10$ & $09 / 11$ & $23 / 11$ & $30 / 11$ & $7 / 12$ \\
\hline 1 & $\begin{array}{l}\text { Jumlah AC } \\
\text { yang selesai }\end{array}$ & 0 & 24 & 27 & 27 & 33 & 53 & 56 \\
\hline 2 & $\begin{array}{l}\text { AC Posisi } \\
\text { Temuan }\end{array}$ & 54 & 21 & 14 & 14 & 13 & 9 & 7 \\
\hline 3 & $\begin{array}{l}\text { AC Posisi } \\
\text { Penawaran }\end{array}$ & 0 & 0 & 14 & 0 & 0 & 0 & 0 \\
\hline 4 & $\begin{array}{l}\text { AC Selesai } \\
\text { POSSis RF }\end{array}$ & 0 & 0 & 0 & 14 & 14 & 14 & 14 \\
\hline 5 & $\begin{array}{l}\text { AC Posisi } \\
\text { PO/IIPP }\end{array}$ & 5 & 5 & 1 & 1 & 1 & 0 & 0 \\
\hline 6 & BAST PM & 0 & 0 & 0 & 0 & 0 & 0 & 0 \\
\hline 7 & PENAGGHAN & 0 & 0 & 0 & 0 & 0 & 0 & 0 \\
\hline TOTAL: & 54 & 50 & 56 & 56 & 61 & 76 & 77 \\
\hline \multicolumn{2}{|c|}{ PROGRESS: } & $50 \%$ & $42 \%$ & $25 \%$ & $25 \%$ & $21 \%$ & $12 \%$ & $9 \%$ \\
\hline
\end{tabular}

\section{SIMPULAN}

Beberapa simpulan yang dapat diambil dari penerapan lean canvas pada project corporate entrepreneurship yaitu:

1. Lean canvas sangat bermanfaat untuk dapat melihat model project corporate entrepreneurship dan keterkaitan sembilan blok di dalam lean canvas.

2. Kendala yang cukup sulit di dalam mengisi key metric dan unfair advantage di dalam lean canvas

3. Lean canvas sangat mudah di dalam melakukan validasi sebuah project corporate entrepreneurship, karena di dalamnya ada key metric, sehingga pencapain keberhasilan dari sebuah project corporate entrepreneurship dapat terukur (measureable).

\section{SARAN}

1. Untuk penelitian selanjutnya dapat meneliti komponen di dalam lean canvas yang cukup sulit untuk ditemukan yaitu unfair advantage. Sangat menarik untuk dapat meneliti dan mencari pola di dalam menemukan pola unfair advantage secara praktis di dalam setiap project corporate entrepreneurship.

2. Untuk penelitian selanjutnya dapat khusus meneliti cara menentukan dan menemukan unique value propotition secara praktis di dalam project corporate entrepreneurship. Kunci dari project corporate entrepreneurship adalah unique value propotition yang ditawarkan sesuai dengan yang dibutuhkan oleh segment market.

3. Untuk penelitian selanjutnya dapat melakukan penelitian untuk dapat menentukan pengukuran yang tepat di dalam komponen key metric dan 
menentukan indikator pengukuran yang tepat sasaran. Project yang baik adalah yang dapat terukur (measureable).

\section{DAFTAR KEPUSTAKAAN}

Amir, M. Taufiq, 2010, Memahami Corporate Entrepreneurship, http:// corpreneur.blogspot.com/ 2010/07/ memahami-corporate-entrepreneurs hip.html, diakses tanggal 7 Juni 2018.

Blank, Steve and Bob Dorf, 2012, The StartUp Owner's Manual, K \& S Ranch, Inc., California.

Canvanizer.com, 2012, Creat a New Lean Canvas, https://canvanizer. com/new/lean-canvas, diakses tanggal 7 Juni 2018.

Creswell, J. W., 2014, Research Design: Qualitative, Quantitative, and Mixed Methods Approach, $4^{\text {th }}$ Edition, Sage Publications Inc., California.

Doran, G. T., 1981, There's A S.M.A.R.T. Way to Write Management's Goals and Objectives, Management Review, AMA Forum.

Ginsberg, Ari and William Guth, 1990, Corporate Entrepreneurship, Strategic Management Journal.

Harianto, Eric, 2015, Model of Individual Characteristics, Corporate Culture, Entrepreneurial Leadership and Reward System for Corporate Entrepreneurship and Its Impact on Manager Performance.

Lawlor, K. Blaine and Martin J. Hornyak, 2012, Smart Goals: How The Application of Smart Goals can Contribute to Achievement of Stu- dent Learning Outcomes, Development in Business Simulation and Experiental Learning, Vol. 39, page 259-267.

Maerz, Jennifer, 2016, Scaling Lean, https://leanstartup.co/scaling-lean/, diakses tanggal 7 Juni 2018.

Maurya, Ash, 2012, Running Lean: Iterate From Plan A to A Plan That Works, Second Edition, O'Reilly: Sebastopol, California.

Maurya, Ash, 2012, Why Lean Canvas VSBusiness Model Canvas?, https:// blog.leanstack.com/why-leancanvas -vs-business-modelcanvasaf62c0f2 50f0, diakses tanggal 7 Juni 2018.

Maurya, Ash, 2016, Scaling Lean: Mastering The Key Metrics For Startup Growth, Pinguin Publishing Group.

Osterwalder, Alexander and Yves Pigneur, 2012, Business Model Generation, Kompas Gramedia, Jakarta.

Pranoto, 2012, Panduan Singkat Penelitian Kualitatif, http://www. bppptegal.com/v1/index.php?option =com_content $\&$ view $=$ article\&id $=1$ 62:panduan-singkat-penelitian kua litatif\&catid=44: artikel\&Itemid=85, diakses tanggal 7 Juni 2018.

Realtimeboard, 2011, Work on your startup with Lean Canvas, https:// realtimeboard.com/examples/leancanvas/, diakses tanggal 7 Juni 2018.

Ries, Eric, 2009, Validated Learning About Customer, http://www.startup lessonslearned.com/2009/04/validat ed-learning-about-customers.html, diakses tanggal 17 Juni 2018. 
Ries, Eric, 2011, The Lean Startup, Crown Business, New York.

Ries, Eric, 2011a, The Lean Startup How Constant Innovation Creates Radically Successful Businesses, Portfolio Penguin, United Kingdom.

Ries, Eric, 2011b, Build Measure Learn Uncertainty Waste Value.

Ries, Eric, 2016, Startup Success can be Engineered by Following The Process, Which Means It can be Learned, Which Means It can be Taught, http://theleanstartup.com/ principles, diakses pada 7 Juni 2018.

Sharma, Pramodita and James J. Chrisman, 1999, Toward A Reconciliation of The Definitional Issues in The Field of Corporate Entrepreneurship, Entrepreneurship Theory and Practice.

Shift Indonesia, 2018, 5 Tahap Menyusun Target dengan Benar, http://shiftindonesia.com/smart-goa ls-5-tahap-menyusun-target-dengan -benar/, diakses pada 7 Juni 2018.
The Jakarta Consulting Group, 2014, Corporate Entrepreneurship, http:// www.jakartaconsulting.com/publica tions/articles/corporate-culture/corp orate-entrepreneurship, diakses pada tanggal 7 Juni 2018.

Website Universitas Ciputra, 2018, https://www.uc.ac.id/, diakses tanggal 7 Juni 2018.

Wikipedia Universitas Ciputra, 2018, https://id.wikipedia.org/wiki/Univer sitas_Ciputra, diakses tanggal 7 Juni 2018.

Yusuf, Angeline, 2013, Analisa Pengaruh Corporate Entrepreneurship Terhadap Kinerja Perusahaan, Agora, Vol. 1, No. 3.

Zahra, Shaker A., 1996, Goverance, Ownership, and Corporate Entrepreneurship: The Moderating Impact of Industry Technological Opportunities, The Academy of Management Journal, Vol. 39, No. 6, page 1713-1735. 